\title{
Ciudad de flujos e infraestructura. La evolución metropolitana en la zona Pacífico del Canal de Panamá
}

\author{
Andrey Hernández Meza
}

Artículo

Afiliación: Université Sorbonne-Nouvelle, Francia.

E-mail: nicoa_84@yahoo.com

Recibido: 30 de septiembre del 2019

Aceptado: 29 de abril del 2020

\section{Andrey Hernández Meza}

Doctor en Geografía Económica y Ordenamiento Urbano. Universidad Sorbonne-Nouvelle/ IHEAL, París Francia. Máster en Investigación: Ciencias para el Medio Ambiente y el Desarrollo Sostenible Universidad de La Rochelle, Francia. Bachiller en Geografía, Universidad de Costa Rica. Cargos: Consultor en análisis internacional y ordenamiento territorial. Profesor contractual en la Universidad Sorbonne Nouvelle y el Institut Diderot en París.

\begin{abstract}
Resumen
El Área Metropolitana Pacífica de Ciudad de Panamá se ha caracterizado por su énfasis en el sector de servicios, lo cual ha llevado a cambios en la dinámica y la morfología, acelerándose debido a la inversión extranjera. Además, el país ha tenido el reto de incorporar las áreas revertidas por parte de los Estados Unidos de la antigua Zona del Canal en el proceso de metropolización. El Gobierno ha debido manejar la inserción de estos espacios urbanos completamente desarrollados, los cuales abarcan más de tres veces el área de la Capital en la dinámica metropolitana. Por otro lado, en el área del Centro Bancario Internacional, desde hace dos administraciones, en el plan de ordenamiento territorial de Ciudad de Panamá se creó la idea de un proceso de honkonización, el cual consiste en una apertura más agresiva de los mercados, adoptando el modelo de desarrollo de esta isla asiática, o como prefiere llamarla el expresidente Ricardo Martinelli: "la Dubái de las Américas", haciendo énfasis en los nuevos mercados en aviación y transporte de bienes. Este artículo busca realizar los primeros pasos en la zona para un análisis, por medio de la geografía económica y el ordenamiento territorial. Se intenta mostrar cómo se ha llevado a cabo la reciente metropolización en el Área Metropolitana Pacífica, provocada por la inversión extranjera en el Centro Bancario Internacional y cómo en las Áreas Revertidas con el proyecto de Ciudad del Saber se ha llevado a una transformación urbana de gran escala.
\end{abstract}

Palabras clave: áreas revertidas; Ciudad de Panamá; inversión extranjera; metropolización.

City of fluxes and in infrastructure: The metropolitan evolution in the Panama Canal's Pacific Zone

\section{Abstract:}

The Pacific Metropolitan Area of Panama City is well known for its emphasis in the services sector, which has caused changes in the dynamic and the morphology, speeding up due the foreign investment. Further, the country have had the challenge to incorporate the reversed areas by the United Stated from the former Zona del Canal in the process of metropolization. The Government have had to manage the insertion of this completely developed urban spaces which embrace three times more the Capital area in the dynamic metropolis. On the other hand, in the Banking International Center area, since two administrations, in the plan of territorial ordering of Panama City has been created the idea of a honkonization process, which consist in a more aggressive aperture of the markets, adopting the model of develop from this asian island, or as the former president Ricardo Martinelli likes to call it: "The America's Dubai", making emphasis in the new markets of aviation and transportation of assets. This article seeks to realize the first steps in the zone for an analysis, helped by economic geography and the territorial ordering. It tries to show up how has been build the recent metropolization in the Pacific Metropolitan Area, induced by the foreign investment in the Banking International Center and how in the Areas Revertidas along with the project Ciudad del Saber have made an urban transformation of big scale.

Keywords: reverted areas; Panama City; foreign inversion; metropolisation. 


\section{Introducción}

$E$

n el Área Metropolitana Pacífica, se está desarrollando una dinamización acelerada tanto en la capital panameña como en las zonas circundantes. Aunque la ciudad siempre se ha caracterizado por su tradición y énfasis en el sector de servicios, el impacto de la inversión extranjera se ha visto marcado a gran escala en los últimos diez años (Luna \& Sánchez, 2009). Desde hace dos administraciones presidenciales, para Ciudad de Panamá se creó la idea de un proceso de honkonización, o, como prefiere llamarla el expresidente Ricardo Martinelli, la "Dubái de las Américas". Lo anterior fue un intento de descentralización en el cual se presenta un modelo que permite "aux grandes villes de rayonner et ainsi d'insérer le pays dans la mondialisation... dont, la métropolisation n'est pas perçue comme une dynamique affectant l'ensemble du territoire national, mais uniquement les grandes villes" (Ghorra-Gobin, 2015, p. 42).

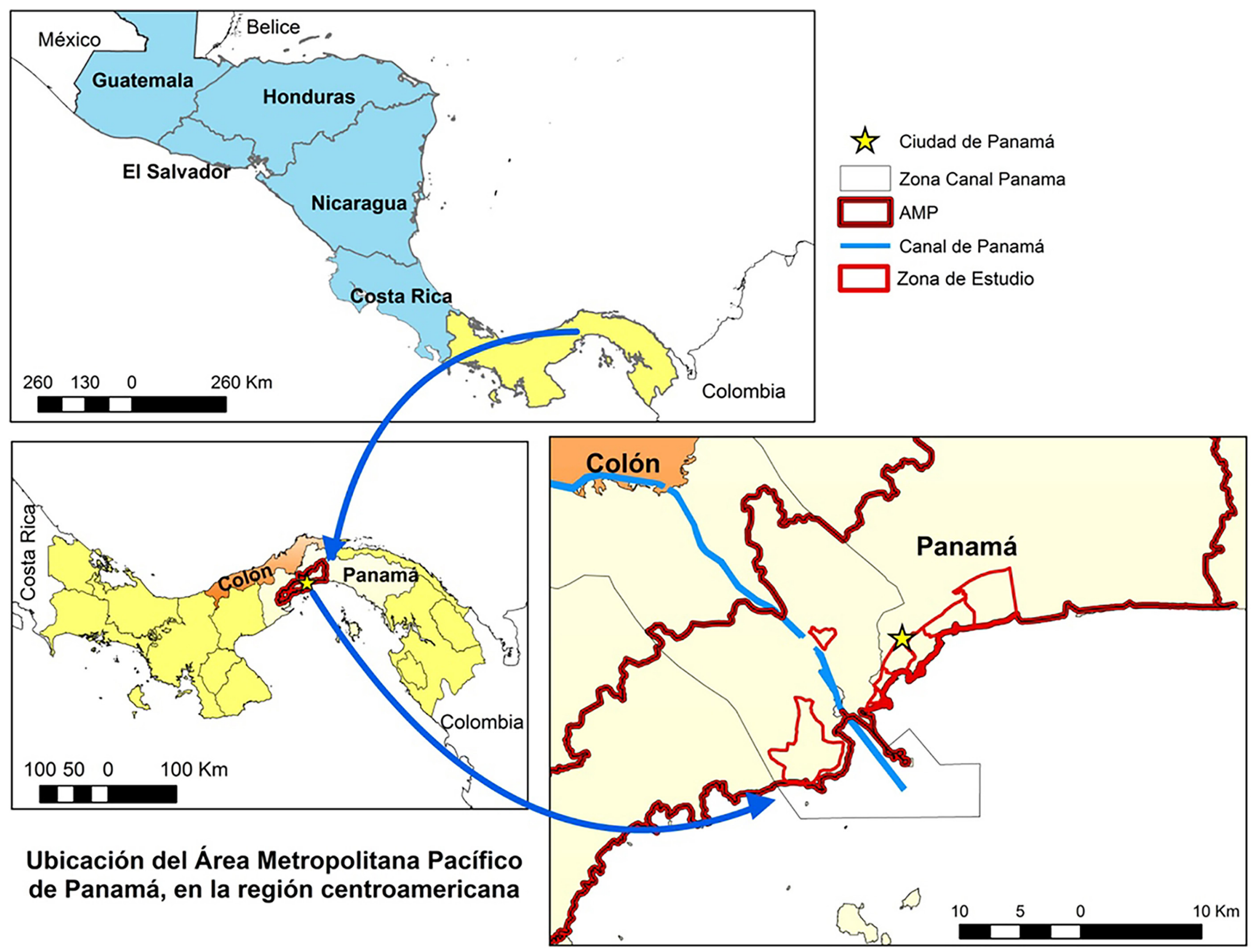

Figura 1. Mapa de la situación geográfica de la zona de estudio en Centroamérica.

Fuente: Elaboración propia, 2017, Trabajo de campo, Smithsonian, 2010.
Estas señales se observan sobre todo en el desarrollo de la infraestructura urbana tanto en lo privado como en lo público, donde el sector de la construcción es la principal compradora de insumos nacionales y mano de obra (Gordón Canto, 2015). Según datos del Instituto Nacional de Estadística y Censos (INEC, 2015), porcentualmente los principales aportes en el sector de servicios al PIB panameño son la construcción y los bienes inmuebles con un $17.4 \%$, esto gracias al desarrollo de nuevos megaproyectos como la primera línea de Metro. Además, el transporte, el almacenamiento y las comunicaciones generan $25.1 \%$, la intermediación financiera cubre $7.8 \%$ y las actividades empresariales, inmobiliarias y de alquiler generan $9.7 \%$ del Producto Interno Bruto.

Así, Ciudad de Panamá es vista según Rivera (2011) como "la puerta de entrada para contribuir con la región" gracias a una conectividad del país con toda Centroamérica a través de vuelos directos y una economía abierta. Lo anterior se refuerza con lo dicho por parte del ministro de Comercio de Panamá, Frank George de Lima, en el Foro 
Latinoamericano de Economía celebrado en París en junio de 2013, en el que expresó que existe una fuerte diversificación de la economía gracias al Área Económica Especial Panamá-Pacífico, a un desarrollado centro de telecomunicaciones y, lógicamente, al Centro Bancario Internacional.

Este artículo tiene como objetivo mostrar un primer acercamiento en la investigación del proceso de metropolización que se ha llevado a cabo en el Área Metropolitana Pacífica desde el análisis de la geografía-económica. Por lo tanto, se busca responder a la pregunta de cómo la nueva dinámica de la inversión extranjera en Ciudad de Panamá y las Áreas Revertidas ha llevado a una transformación urbana a escala local. Lo anterior ha traído impactos directos en el ordenamiento territorial, la sociedad capitalina y la apertura a nuevos mercados, comprendiendo la dinámica urbana en la zona. Para poder demostrarlo, se basó en una metodología de investigación donde se recopiló información por medio del trabajo de campo, en el cual se realizaron: entrevistas a los encargados del ordenamiento territorial de los sitios estudiados (Municipalidad de Panamá, Administración de la Áreas Revertidas, MIVIOT, etc.), recopilación de datos estadísticos en las bibliotecas de la Contraloría de la República y la oficina encargada de las Áreas Revertidas y un análisis espacial por medio de la observación. Además se abordó el tema con desarrolladores de los distintos proyectos antes mencionados.

Para comprender los fenómenos espaciales se expondrá el estudio en tres partes. La primera es el Centro Bancario Internacional que abarca los sectores Obarrio y el Cangrejo y cuya dinámica podemos encontrar hasta las zonas de Punta Paitilla, Punta Pacífico y Costa del Este de forma inmediata. Asimismo, el proceso de gentrificación del centro histórico a través del cual, si bien la ciudad se ha encargado de mejorar su aspecto estético, se ha dado un proceso de expulsión de la población local para dar paso a casas de lujo y hoteles de alto costo, los cuales se encuentran fuera del alcance de la población promedio panameña. Además, se analizará el motor de cambio en la apertura comercial y atracción de inversión en Ciudad de Panamá y las Áreas Revertidas de la antigua Zona del Canal, donde "se respiran aires nuevos de metropolización". Estos terrenos fueron devueltos al país por parte de los Estados Unidos y consisten en antiguos asentamientos civiles y militares que velaban por el funcionamiento y protección de la vía marítima. Para finalizar, como tercer punto, se realizará un acercamiento a los aspectos de la gobernanza, la toma de decisión sobre el desarrollo metropolitano del AMP y las deseconomías que se perciben tanto desde el punto de vista del sector privado como público.

\section{Ciudad de Panamá, la honkonización de una metrópolis Centroamericana}

El Centro Bancario Internacional es lo primero que atrae la vista a la hora de llegar a Ciudad de Panamá. Éste es el sitio donde se encuentra el principal sector financiero del país y de la región Centroamericana. Este paisaje urbano inmediatamente captura al espectador, buscando crear una imagen que recuerde la honkonización de la capital panameña. La zona ha experimentado un fuerte crecimiento en el desarrollo de edificios de gran altura en donde se establecen apartamentos y oficinas, lo cual ha llevado a una actividad inmobiliaria muy dinámica. En Panamá se ha consolidado un fenómeno recurrente en América Latina: el aumento de la población urbana que busca una mayor densificación (Cárdenas, Cabrera y Pittí, 2015), destinada a un segmento de población de alto poder adquisitivo.

La idea de utilizar un modelo como el de Hong Kong para perfilar la metropolización de Ciudad de Panamá puede revelar ciertos criterios urbanos, los cuales pueden ser de carácter financiero, constructivo y social. Se expondrán, en pocas líneas, los grandes rasgos de la ciudad en la cual se está inspirando la capital panameña. Se trata de una ciudad asiática perteneciente a China, la cual fue devuelta después de décadas de control británico. Es un modelo capitalista inglés que se aplicó en la China comunista, llevando a crear uno de los centros financieros más importantes del mundo. Además, es una economía dirigida al sector terciario en su mayoría, dando facilidades en la implantación de compañías off shore con un nivel de tributación simple (CIA, 2017). El 
perfil de la construcción de rascacielos, el cual busca una densificación de la ciudad, es otro aspecto que se busca imitar. Hong Kong es una de las ciudades más densamente pobladas del mundo, llegando a contar con una población 100\% urbana (Heritage Foundation, 2016).

Después deaclarar el panorama que se busca en Ciudad de Panamá, se puede comenzar a hacer el análisis urbano. La capital se define como una de las más modernas de América Latina, tanto a nivel constructivo como a nivel económico, con dinámicas que buscan semejar las de países desarrollados (de Brown, 2014). Lo anterior se da con la idea de mejorar la competitividad del país a través de proyectos como el saneamiento de la Bahía de Panamá, la construcción de la Línea 1 del Metro y la ampliación de puentes y carreteras, entre otros (Brown y Luna, 2013).

\section{Flujos del urbanismo en Ciudad de Panamá}

Ciudad de Panamá ostenta un urbanismo que resalta por su poca planificación a la hora de ordenar la dirección de la ampliación de la ciudad. Lo anterior se basa en la dinámica que se presenta en los proyectos de construcción que se han desarrollado. La limitante de la zona del Canal, que existió hasta 1999, estableció una demarcación para la expansión de la ciudad hacia el oeste, teniendo como punto de partida el Casco Viejo, sitio de emplazamiento principal a inicios del siglo XX e inmediatamente colindante con el área de acceso restringido impuesta por los Estados Unidos. El lugar cuenta con un evidente Plan Damero reticular en el que la plaza y la iglesia son los principales centros para luego convertirse en calles que se adaptaban a la línea limítrofe con la antigua zona del Canal.

Para el año de 1970, la aprobación del régimen de propiedad horizontal viene a dar las primeras herramientas para la verticalización paulatina de la Ciudad (CAPAC, 2015). El centro de comercio de la capital había sido desplazado al sector de Calidonia, ya que el crecimiento en el casco histórico era limitado. Por esta razón, se estableció la Municipalidad de Panamá en este sitio, así como el Hospital principal y uno de los edificios que durante mucho tiempo fue emblemático en la ciudad: el Edificio de la Lotería, construido en 1977 y que fuera el de mayor altura en la ciudad durante más de dos décadas (Young, 2013). Hoy no se encuentra ni entre los 50 primeros. Así, queda marcado un crecimiento anárquico de la mancha urbana, partiendo del centro histórico de San Felipe (Casco Viejo) y llevando a una multicentralidad y una fragmentación urbana que desdibujan la expansión territorial (Castro Gómez, 2012).

Sin embargo, durante las décadas de 1970 y 1980, el gobierno militar mantuvo control (lo cual no significa ordenamiento territorial) sobre el desarrollo de proyectos de vivienda e inversiones. Después de la invasión estadounidense en 1989 a Panamá y el establecimiento de un gobierno democráticamente electo, se da paso a la liberación del mercado inmobiliario y a un retroceso del Estado en la toma de decisiones que viene a acelerar los flujos de expansión urbanos, aumentando la fragmentación ya existente (Luna y Sánchez, 2009).

Posteriormente, la inversión inmobiliaria se desplazó al Centro Bancario Internacional, el cual existía en la década de 1970. Después de la liberación del mercado recibe los primeros proyectos de amplitud vertical. En un principio, esta zona fue de vocación residencial con edificios de poca altura donde se establecían las oficinas de los bancos representados en el país (Buendía, 2014). Al no existir un plan de ordenamiento, los empresarios aprovecharon las nuevas ventajas para cambiar la zonificación, creando paulatinamente proyectos horizontales de vivienda y después los rascacielos de hoy en día. Así, para los años de 1990, ya se encontraban las primeras construcciones, como la Platinum Tower de 159 metros (hoy en el puesto 41 en altitud de los edificios más altos de Latinoamérica) que presagiaban el perfil moderno de la ciudad actual (Young, 2013).

Como se pudo apreciar en la Figura 1, para poder explotar la dinámica inmobiliaria, la capital empezó a expandirse hacia el mar con zonas de relleno, como en los casos de Punta Paitilla, Punta Pacífica y Costa del Este (Gordón Canto, 2015). Este último desarrollo se basa completamente en la construcción del Corredor Sur, vía que une 


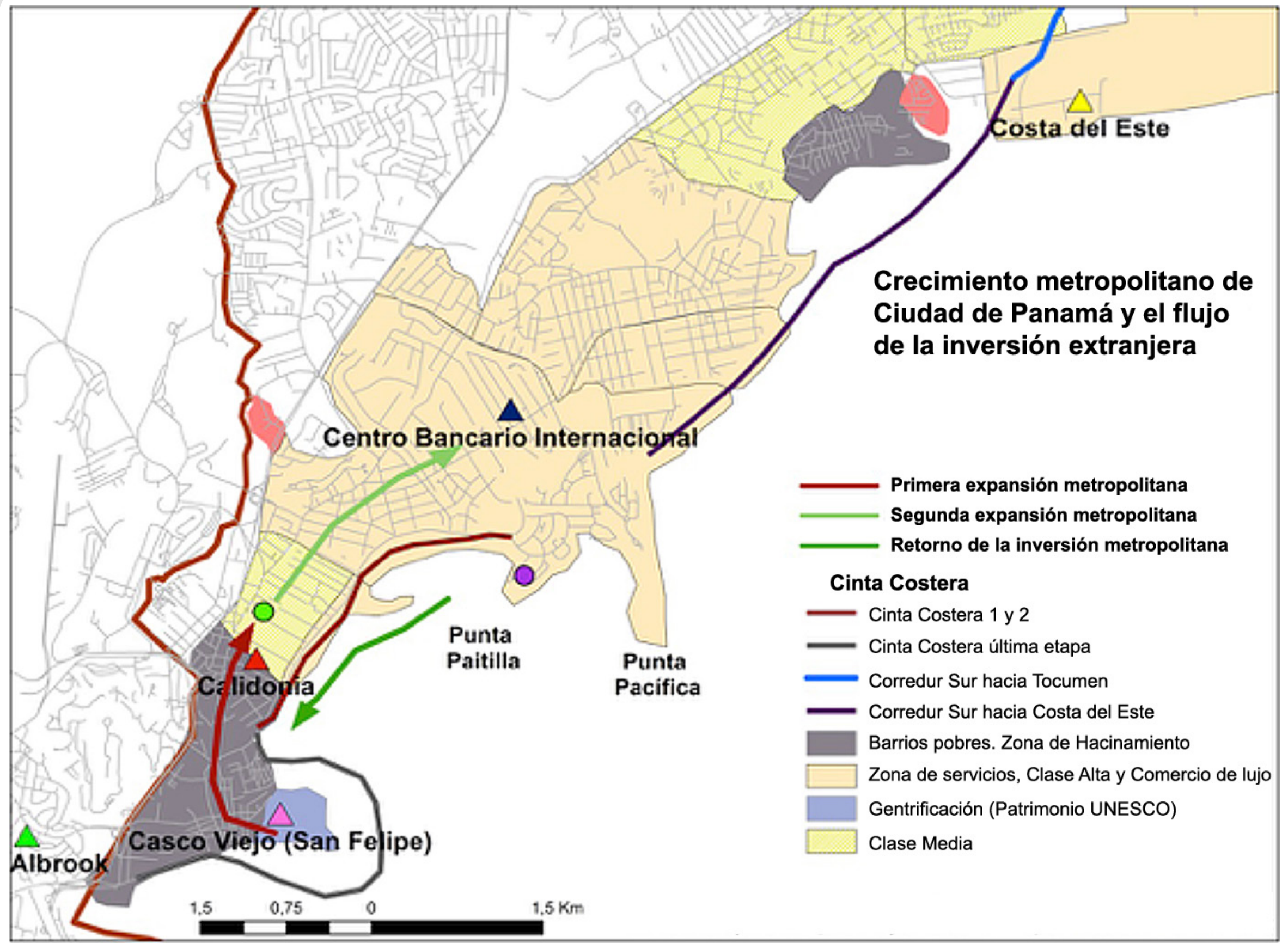

Figura 2. Mapa del crecimiento metropolitano de Ciudad de Panamá y el flujo de la inversión extranjera.

Fuente: Elaboración propia directamente la capital con el Aeropuerto Internacional Tocumen. Sin embargo, durante los últimos 5 años, se ha visto un movimiento en el espacio con respecto al desarrollo de grandes edificaciones que refleja un efecto de "boomerang".

Al expandir la cinta costera, los desarrollos verticales han comenzado a trasladarse hacia el oeste, hacia el centro histórico. Este fenómeno se puede analizar desde diferentes perspectivas. La primera, aprovechar la inversión pública en la mejora urbana costera de la ciudad. La segunda, buscar terrenos hacia la parte pobre de la ciudad en donde el metro cuadrado es más barato para ir desarrollando nuevos proyectos urbanos. Finalmente, acercarse a los nuevos emplazamientos de las Áreas Revertidas, aprovechando las nuevas carreteras que unen a esta zona. Además, este fenómeno se apoya en la gentrificación que está viviendo el Casco Antiguo con la llegada de inversión turística, explotando el centro histórico con aspecto postcolonial y su nombramiento como Patrimonio de la Humanidad.

\section{El Centro Bancario Internacional}

La morfología del lugar se presenta compleja al no haber una sectorización para el establecimiento de la inversión extranjera directa. El mercado inmobiliario y la plusvalía de las diferentes zonas son lo que ordena el establecimiento de los desarrollos. En el sitio se encuentran los principales centros financieros con representación a nivel mundial, como es el caso del Centro Bancario Internacional, además de algunos de los office centers más importantes del país. A lo anterior se le suma la presencia de importantes oficinas del gobierno de la República, como por ejemplo: la Contraloría General, el Ministerio de Economía, las distintas oficinas de la súper intendencia de bancos, centros universitarios privados y los principales centros comerciales o malls del país. 
A partir de los años setenta, este barrio empezó a desarrollarse en la capital, beneficiándose de una actividad bancaria prácticamente libre de impuestos, de circulación de capitales, del secreto bancario y en busca de operaciones offshore (Collin-Delavaud, 2006). Esta zona está compuesta por los barrios de Bella Vista, El Cangrejo, San Francisco, Marbella, Obarrio; finalmente, avanzando hacia Punta Paitilla, Punta Pacífica y Costa del Este. Se le agrega actualmente el fenómeno de retorno a Calidonia, aprovechando la cinta costera (Figura 2). No se puede obviar el boom inmobiliario que se ha dado en esta ciudad desde finales de 1990 y que continuó aún con la crisis del 2008, provocando el crecimiento de rascacielos y dibujando el skyline de la zona (Castro, 2012). La ciudad ha tomado aspecto de "nuevo Miami", mostrándose como polo de inversión pública del país y convirtiéndose en un centro neurálgico de inversión extranjera y establecimiento de transnacionales.

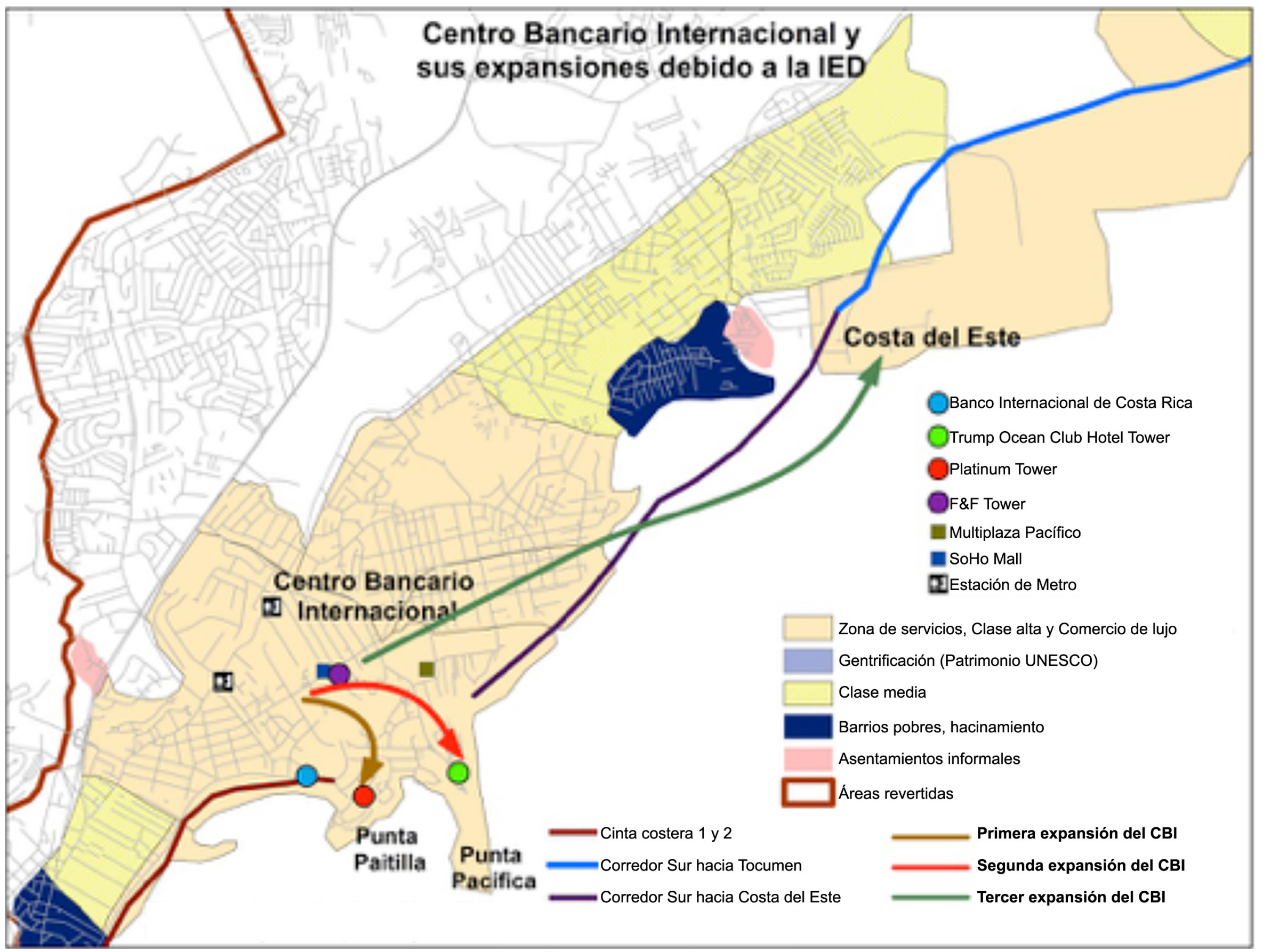

Figura 3. Mapa del Centro Bancario Internacional y sus expansiones debido a la inversión extranjera directa.

Fuente: Elaboración propia. Trabajo de campo 2015 y Smithsonian Tropical Research Institute, 2012.
A De este modo, el Centro Bancario ha modificado su aspecto clásico de casas de familias adineradas al lado de casas más pequeñas donde se podía encontrar una cierta mixtura social. Sin embargo, a partir del año 2000, la tendencia a la construcción de rascacielos y apartamentos de lujo modificó la morfología del sitio sin ninguna planificación zonal debido a la baja intervención estatal, a los intereses privados y a la velocidad de la llegada de los desarrollos (Mata y Rosas, 2014). Así, los detentores de casas de lujo optaron, en su mayoría, por adquirir apartamentos en los nuevos edificios que se construían. Por otra parte, la clase media vendió sus terrenos por la presión que genera la nueva tendencia de "desarrollo" en la ciudad, teniendo que desplazarse fuera del centro debido a la nueva dinámica urbana de alta plusvalía. De este modo, se puede apreciar cómo los que tenían la capacidad económica y hacían mejores ventas de sus propiedades podían optar por una opción de vivienda en las afueras de la ciudad. El primer destino enfocado para esta población fue el oeste de la ciudad, cruzando el puente de Las Américas hacia los sectores de Arraiján, donde se desarrollaron proyectos residenciales con vocación horizontal (Buendía, 2014). 
En el centro bancario, la inversión extranjera se ha vuelto visible, más que todo por el perfil de la ciudad. Desde inicios de los años 2000, se han construido más de 150 rascacielos que sobrepasan los 100 metros de altura. Además, hoy en día, el Centro Bancario Internacional cuenta con 44 edificios de más de 155 metros de altura. El edificio más alto de la ciudad es el Trump Ocean Club Hotel Tower con 70 pisos y 284 metros de elevación (CAPAC, 2015). Dentro de los 35 edificios que superan los 190 metros en América Latina, este sitio cuenta con un total de 25 , lo que corresponde al $71 \%$ del total, mientras que Ciudad de México cuenta con cinco, un 14\% del total, seguido por Santiago y Caracas con dos cada uno, aproximadamente un $6 \%$ y, finalmente, Bogotá con un 1\% (Young, 2013). El único edificio que supera a las mayores elevaciones de Ciudad de Panamá es la Gran Torre de Santiago con 300 metros, unos 16 metros por encima de la Trump Ocean Tower.

No obstante, como se mencionó, esta transformación empezó como una modificación paulatina del uso residencial para luego dar paso a una vocación de negocios. De este modo, se puede afirmar que el boom inmobiliario fue dirigido a un mercado de vivienda, proyectándose principalmente al mercado estadounidense jubilado. Sin embargo, los proyectos no interesaron al principal grupo al cual iba enfocado, provocando una burbuja inmobiliaria (Buendía, 2014) donde se sigue desarrollando para intentar atraer compradores norteamericanos. No obstante, éstos no buscaban una ciudad con malos servicios de transporte para pasar sus últimos años, sino que prefirieron dirigirse al sector de Boquete, conocido por sus atractivas playas. Lo que salva las inversiones es la migración de suramericanos que llegan a Panamá, como lo hicieron primeramente los colombianos y actualmente los venezolanos con alto poder adquisitivo que buscan salir del régimen chavista. Posteriormente, el desarrollo empresarial empieza a situarse en la zona, principalmente por el prestigio que empieza a tener y la cercanía con compañías o centros financieros para hacer negocios.

Esta dinámica se ve reflejada en los números de la Municipalidad de Panamá a la hora de otorgar permisos de construcción y de recaudar impuestos. Se puede observar que las inversiones y las ganancias presentan una tendencia al alza, excepto en el 2011. Por ejemplo, en el 2013, se llegan a recolectar casi ocho millones de balboas tan solo en permisos de construcción. La gran facilidad con la que se otorgan los permisos es la cualidad más flexible del plan de ordenamiento llevado por el MIVIOT, donde se trabaja de manera puntual según el proyecto y, así, se modifica la zona. Se analiza cada proyecto para advertir si va con lo estipulado en las normativas del sector seleccionado, considerando que cada proyecto puede variar según el interés de este para la población o el país (de Brown, 2014). Por lo tanto, se trabaja con tres escalas de planes: plan individual, plan parcial y plan regional, según el tipo de proyecto.

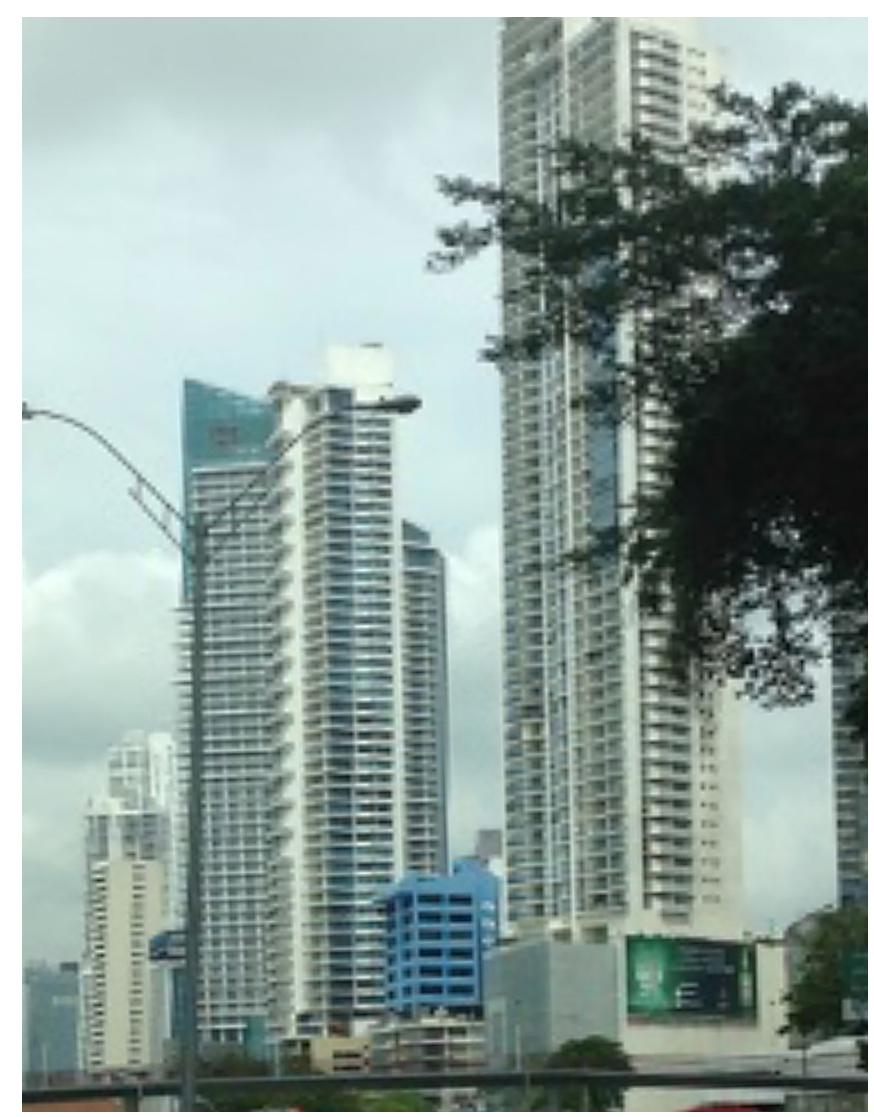

Se observa una expansión del Centro Bancario ya que no existen normas de zonificación ni de contención. Esto modifica la vida interna de los corregimientos, terminando con la vida de barrio y privilegiando un modelo dirigido por los intereses de las inversiones y las personas a quienes van dirigidas (Mata \& Rosas, 2014). El gran desarrollo urbano de la ciudad de Panamá da como resultado "el surgimiento de nuevas realidades que se expresan en la creación de nuevos estilos de vida, así como nuevas formas de consumo" (Castro, 2012, p. 96). En este aspecto, se han instalado grandes centros comerciales de lujo como el SoHo Mall y Multiplaza.

Figura 4. Centro Bancario Ciudad de Panamá. Fuente: Elaboración propia 
Sin embargo, en estos malls las tiendas son de una "categoría" económica mayor y única en Centroamérica, pues cuentan con marcas como Bulgari, Prada, Louis Vuitton, etc. Esto demuestra el tipo de población a la cual se dirigen estos espacios comerciales de recreo, donde la demanda de este tipo de productos es mayor. Lo anterior viene a manifestar el peso que tiene el Centro Bancario Internacional, no solo como un centro de flujos financieros, sino también en los flujos comerciales y de personas. Esta situación se refleja urbanísticamente en el espacio, haciendo que en un área relativamente pequeña converjan grandes intereses internacionales y presionando a la institucionalidad estatal.

Por lo tanto, fuera del área del Canal de Panamá, este es el sector que más inversión pública ha recibido en el área de la construcción. En primer lugar, la cinta costera, proyecto con el cual se une la moderna ciudad del Centro Bancario con el Casco Viejo, Patrimonio de la Humanidad UNESCO, para luego rodear el centro histórico gracias a una carretera construida sobre el mar y, finalmente, llegar hasta el área costera del Chorrillo. Este desarrollo tuvo un costo de más de $\$ 782$ millones de dólares, ganándole al mar más de 26 hectáreas (Soto, 2014), vía por la cual se está "devolviendo" la inversión extranjera hacia el este de la ciudad. Como segundo proyecto se encuentra la primera línea de metro de Centroamérica, la línea 1 del Metro de Panamá. Con un recorrido de norte a sur, une la terminal de buses de Albrook con el Centro Comercial Los Andes, llevando su recorrido por el sector noreste del Centro Bancario (estaciones Iglesia del Carmen y vía Argentina). Una de las mayores modificaciones que se espera para la zonificación de Ciudad de Panamá, con la entrada en funcionamiento del metro, ha sido exigir que los sectores en un radio de menos de 300 metros sean de uso mixto obligatorio (de Brown, 2014; Mata \& Rosas, 2014).

\section{Casco Viejo (San Felipe)}

Hoy en día, San Felipe es una de las zonas que más atrae a los inversores extranjeros que buscan aprovechar la línea de hoteles boutique y restaurantes finos. Creado en 1673 , se trata de la relocalización de la antigua ciudad ubicada al oeste como consecuencia del gran saqueo y posterior incendio por parte del pirata inglés Henry Morgan. Debido a esto, se delineó con las características que la Corona de España exigía para las construcciones urbanas de la época, con una plaza central que marcaba el inicio del plan damero (Tejeira, 2008). Sin embargo, esta área estuvo abandonada durante muchas décadas, poblándose de sectores pobres con edificios vetustos y poco sanitarios. Después de la década de 1970 se pierde como referente físico y simbólico capitalino (Castro, 2012), por más que la casa presidencial se mantuviera allí.

La rehabilitación tardía y lenta, en comparación con otros centros históricos de América Latina, permitió en cierto modo la conservación de los edificios, plazas y calles de las modificaciones modernas de Ciudad de Panamá (Collin-Delavaud, 2011). No obstante, en los últimos 5 años esta "recuperación" se ha llevado de manera voraz y anárquica. De esta forma, los inversores, en lugar de restaurar los edificios, han llevado a cabo la demolición de los mismos, dejando solo las fachadas. Por lo tanto, se pierde la riqueza de la estructura, incluyendo los patios interiores, dejando un cascarón con una arquitectura interior completamente nueva, la cual, en la mayoría de los casos, no es armónica con el diseño histórico.

Figura 5. Casco Antiguo, Ciudad de Panamá. Fuente: Elaboración propia.
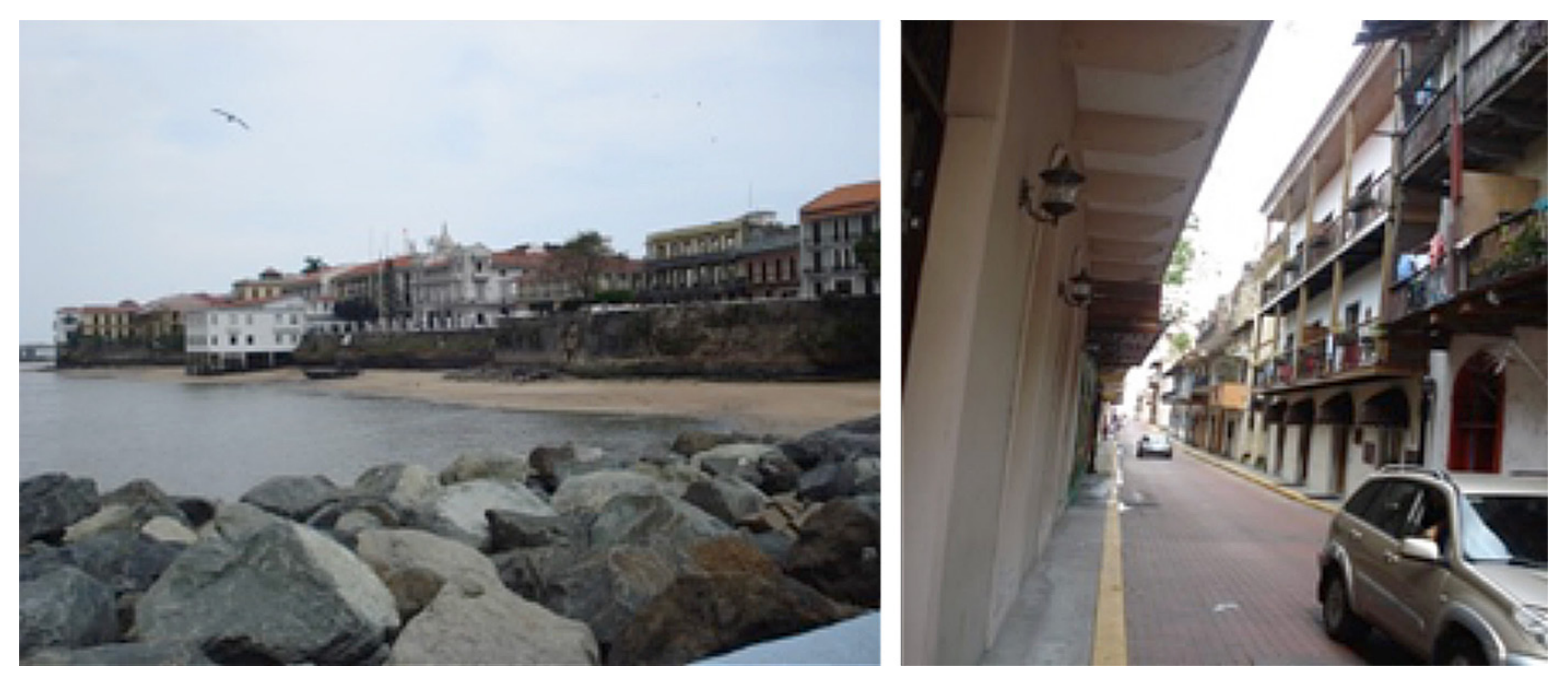
Como se puede apreciar en las imágenes, la gentrificación es evidente en el área, siendo parte de la recuperación de zonas históricas en diferentes partes de Latinoamérica. No obstante, el proceso que se promueve en Panamá sin controles o límites a la afectación de estructuras históricas puede llevar a la UNESCO a quitarle de la lista de Patrimonio de la Humanidad, reconocimiento otorgado en 1997 (Tejeira, 2008; Collin-Delavaud, 2011). Los procesos de inversión extranjera han tenido impacto importante en el Casco Viejo donde se evidencia que, al dejar sin restricción a los inversores, prima la ganancia económica sobre un proceso de restauración regulada.

\section{Las Áreas Revertidas, el territorio devuelto con un área ya desarrollada, atracción para un nuevo tipo de inversión extranjera}

No se puede realizar un estudio sobre Ciudad de Panamá sin mencionar de una u otra manera el Canal de Panamá. No solo la capital se adaptó a la vía transoceánica, sino que todo el país depende de su existencia debido al juego geopolítico que conllevó la construcción de la obra. En un primer momento, con el intento francés a través del proyecto de Ferdinand de Lesseps, Colombia buscaba afianzar su presencia en el istmo panameño. Posteriormente, con el fracaso del Canal francés, se venden las acciones a los Estados Unidos por medio del tratado Herrán-Hay de 1903, firmado con Colombia y el cual autoriza la construcción del Canal (UABR, 1998b). Debido a la importancia geopolítica del canal, a los estadounidenses les convenía la independencia. En consecuencia, estos aprovechan la coyuntura entre colombianos y panameños y apoyan a los segundos para que obtengan su independencia. De este modo, el 18 de noviembre de 1903 se firma el tratado Hay-Bunau Varilla entre Estados Unidos y Panamá, pocos días después de la independencia que separa Panamá de Colombia (ACOBIR, 1998).

Con lo anterior, se inaugura la presencia de los norteamericanos en Panamá. Se les conceden además del área náutica, cinco millas de extensión en ambas márgenes del Canal. Estos derechos, según el tratado Hay-Bunau Varilla, son otorgados a perpetuidad, con jurisdicción policial y judicial ejercida exclusivamente por los estadounidenses (Herrera y Castro, 1986). Igualmente bajo estos criterios, se les otorgan las islas de Naos, Perico, Flamenco y Culebra. De esta forma, una gran extensión de tierra divide al país bajo la jurisdicción estadounidense, ya que no se permitía el libre tránsito. Esto sumado a la permanente presencia de soldados y armamento del ejército con la vocación de proteger el funcionamiento del Canal.

Lo anterior lleva a crear un enclave dentro del territorio panameño con desarrollo, infraestructura y población propios bajo la bandera de los Estados Unidos. Esta situación se mantuvo hasta la década de 1970 cuando empezaron a ser frecuentes las manifestaciones de los panameños para recuperar la soberanía del área ocupada. Los principales exponentes fueron los estudiantes de años superiores de liceo y universitarios. Después de múltiples incidentes, se llega a un acuerdo con el gobierno estadounidense que lleva a la firma del tratado Torrijos-Carter en 1977 (UABR, 1998). Con este se da inicio al proceso de reversión del Canal de Panamá y sus áreas aledañas. Así, en la siguiente sección se identificarán las Áreas Revertidas que recibieron los panameños, así como los principales equipamientos que se encontraban en los sitios estudiados por este trabajo, es decir, dos proyectos innovadores en la región centroamericana: Ciudad del Saber y Panamá Pacífico.

\section{¿En qué consisten las Áreas Revertidas?}

Con la firma del tratado Torrijos-Carter en 1977, se empieza el proceso de reversión de una de las principales obras de ingeniería en el continente americano. El documento, firmado en 1903, le otorgaba a los Estados Unidos la soberanía a perpetuidad sobre 147,400 hectáreas (UABR, 1999a). En total, según estimaciones de la Unidad Administrativa de Bienes Revertidos, los estadounidenses poseían 553 millas cuadradas de las cuales 362 se encontraban en tierras y 191 en espejos de agua. Los 
norteamericanos manejaron la zona libremente dentro de un espacio de 10 millas, cinco de cada lado del margen del canal más las islas del Pacífico: Noas, Culebra, Perico y Flamenco. Así, crearon una división político-administrativa propia en la que existían dos distritos principales, Balboa y Cristóbal. El primero viene a ser en la actualidad parte de Ciudad de Panamá, mientras que el segundo actualmente corresponde al área de Colón (Barrera, 2015).

El punto central de las operaciones y la dinámica diaria de la zona del canal actualmente corresponde al sector de Balboa, el cual se encontraba al lado de la capital panameña. Dentro de los centros civiles con mayor importancia, se encontraban: Ancón, Arraiján, Balboa Heights, Estación Cuarentena, Hospital (psiquiátrico), Gamboa y Miraflores (ARI, 1994). Sin embargo, la importancia estratégica que tiene el canal dentro de la geopolítica mundial obligó a los estadounidenses a emplazar destacamentos militares. Para proteger la vía marítima se crearon dos divisiones, Pacífico y Atlántico, las cuales se equiparon de 14 bases militares. En el primer sector se encontraban las bases de Clayton, Amador, Grant, Kobbe, Rodman, Albrook y Howard Query Heigths, de las cuales a las dos últimas se les construyó un aeropuerto a cada una. Una de ellas es la pista Howard, la más grande de Centroamérica. El segundo sector tenía las bases de Sherman, San Lorenzo, De Lesseps, Randolph, Gullick y Davis (ARI, 1994).

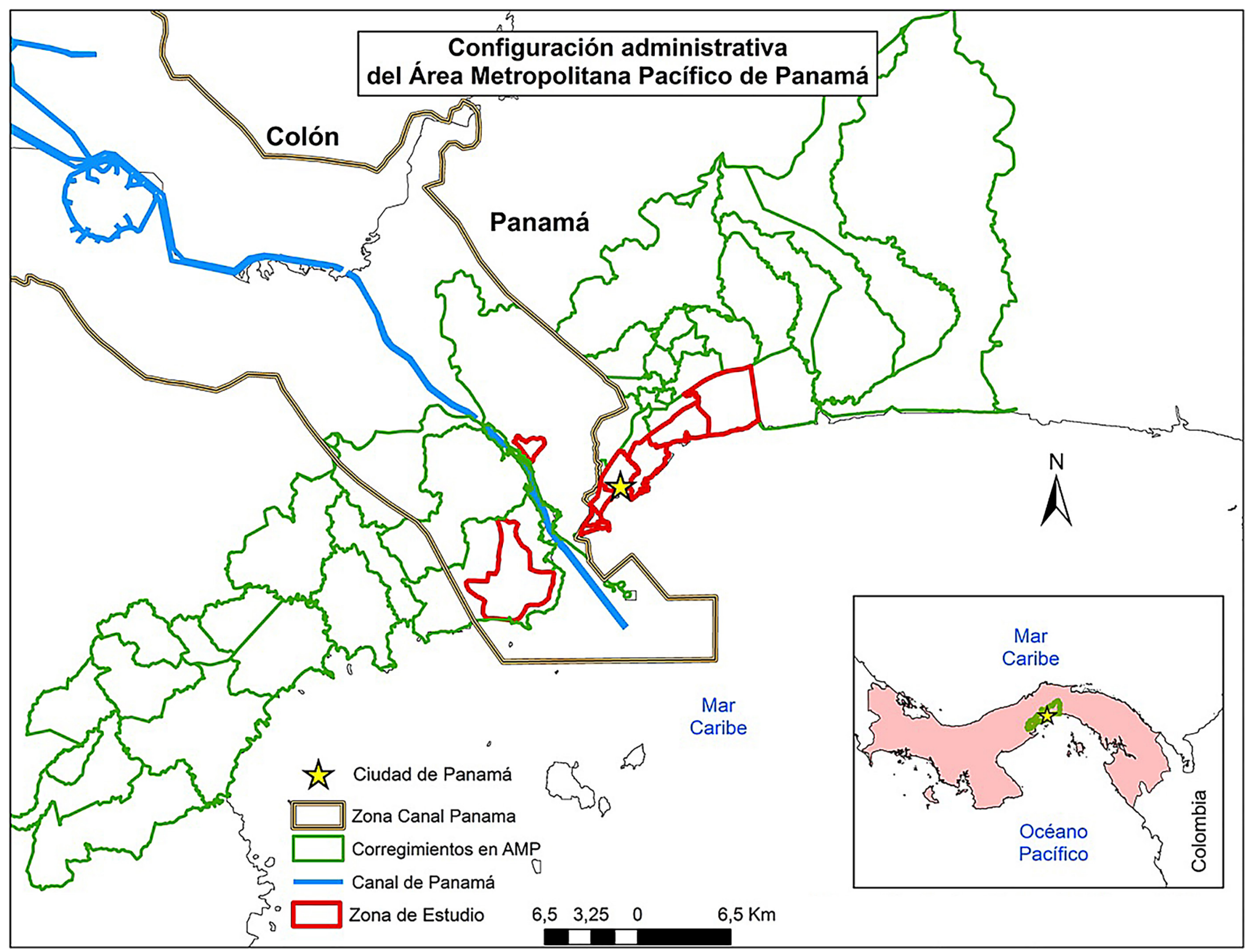

Figura 6. División distrital de la Zona del Canal en la época estadounidense y comparación con Ciudad de Panamá.

Fuente: Elaboración propia.
Es así como a partir del primero de octubre de 1979, los panameños empezaron a recuperar paulatinamente la zona del canal. Se construyeron pequeñas ciudades completamente equipadas dentro del área del canal, las cuales contaban con centros de entretenimiento como cines, teatros, centros polideportivos, escuelas, etc. La creación de las nuevas instituciones debía ser inmediata, ya que se recuperaron el $64 \%$ de las tierras en los primeros cinco años. Esta transición llevó 20 años, concluyendo el 31 de diciembre de 1999 cuando se desciende la bandera de los Estados Unidos por última vez y se iza la de Panamá, marcando la salida de los últimos cuerpos militares extranjeros 
en el país (Collin-Delavaud, 2011). De este modo se termina la reunificación del país y comienza la nueva dinámica de la Ciudad de Panamá con las áreas completas.

Para poder tomar posesión de las áreas, así como de las operaciones del canal, el país tuvo la necesidad de crear toda una nueva institucionalidad para manejar las reversiones. Los panameños tenían que seguir con el correcto funcionamiento de la vía transoceánica y mantenimiento de los bienes, pero más importante aún era el reto de incluir las nuevas áreas urbanas en la dinámica metropolitana (Barrera, 2015). Para las actividades del canal y la cuenca, se crean instituciones como la Dirección Ejecutiva para asuntos del tratado, la Autoridad de Canal, la Comisión del Canal y la Autoridad de la Región Interoceánica (ARI) (ARI, 1994). De este modo, la Comisión del Canal fue la responsable de las fusiones hasta el 31 de diciembre de 1999. Ese mismo día entra en función la Autoridad del Canal de Panamá, responsable de las operaciones de la vía maritima.

Los panameños reciben grandes áreas construidas, las cuales deben ser integradas en la dinámica metropolitana de la capital. Esta área de baja densidad de población, donde la mayoría eran extranjeros, posee gran variedad de escenarios: espejos de agua, masas boscosas, biodiversidad, asentamientos urbanos y rurales, además de una docena de cuarteles, áreas de entrenamiento, hangares, etc. (UABR, 1999a). Reconvirtiendo los emplazamientos en sitios civiles, la ARI posee el monopolio estatal para evaluar, crear un plan maestro y vender (Collin-Delavaud, 2006). Por lo tanto, siguiendo las ideas neoliberales de la década de 1990, se prioriza la tercerización de la zona, obstaculizando al pueblo panameño para adquirir bienes que fueron subastados y comprados por extranjeros (Gordón Canto, 2015). Por ejemplo, para 1996, todos los puertos del área del canal fueron privatizados (Collin-Delavaud, 2011).

Tipos de manejo llevados a cabo en las Áreas Revertidas: el caso de Ciudad del Saber

Para poder comprender mejor el manejo que predomina en la antigua zona estadounidense del canal, se ha realizado el estudio de dos proyectos, como se mencionó en capítulos anteriores. Lo primero que resalta en ambos es la comunicación con el centro de la capital, ya que los transportes no son muy eficientes. En el primer caso, Ciudad del Saber, el servicio de buses desde la terminal principal de Albrook, también en zona revertida, termina temprano y su frecuencia es poca. En el caso de Panamá Pacífico, no hay servicio de bus metropolitano a esta zona, lo que limita su acceso al vehículo particular o taxi sumado a que se encuentra del "otro lado" del canal. Este primer indicio muestra que la conexión con el área central no es fluida, dificultándose cuanto más se aleja de la capital a pesar de que las distancias no son considerables.

\section{Ciudad del Saber, proyecto único en la región centroamericana}

El proyecto se encuentra en el sector de una antigua base militar estadounidense, el Fuerte Clayton, ubicado justo en frente de las Esclusas de Miraflores. Esta área se encontraba completamente equipada y en perfectas condiciones gracias al excelente mantenimiento que recibió durante la ocupación estadounidense. Además, fue una de las últimas en ser revertidas. Los bienes que se recibieron de esta antigua base son numerosos y de gran tamaño. Alli se encontraba una importante población militar y civil, familiares de los militares de altos rangos y de los operadores del canal.

Así, la Ciudad del Saber se ubica en 120 de las 880ha del complejo, de los cuales son ahora los únicos "propietarios". Según la ARI, esta recibió por parte de los Estados Unidos (UABR, 1999a):

- Centro recreativo con cancha de bolos de ocho pistas y área de comidas rápidas.

Motel de 35 habitaciones y cinco apartamentos.

Dos clubes comunitarios con capacidad para 375 y 150 personas respectivamente. 
Gimnasio y piscina semi olímpica.

Estación de gasolina con centro de reparación de automóviles.

Teatro para 876 espectadores.

Estación de bomberos.

Dos escuelas primarias privadas para 330 y 800 estudiantes.

Estación de policía y centro de detención.

Edificio de oficinas del alcalde local y oficina de correos.

Hospital de $24500 \mathrm{~m}^{2}$.

Dormitorios para 1754 personas.

Almacenes y depósitos de $38000 \mathrm{~m}^{2}$.

Viviendas familiares: una séxtuple, 205 cuádruples, 267 duplex, y 32 sencillas. Además de 229 de cuatro cuartos y 779 de tres cuartos.
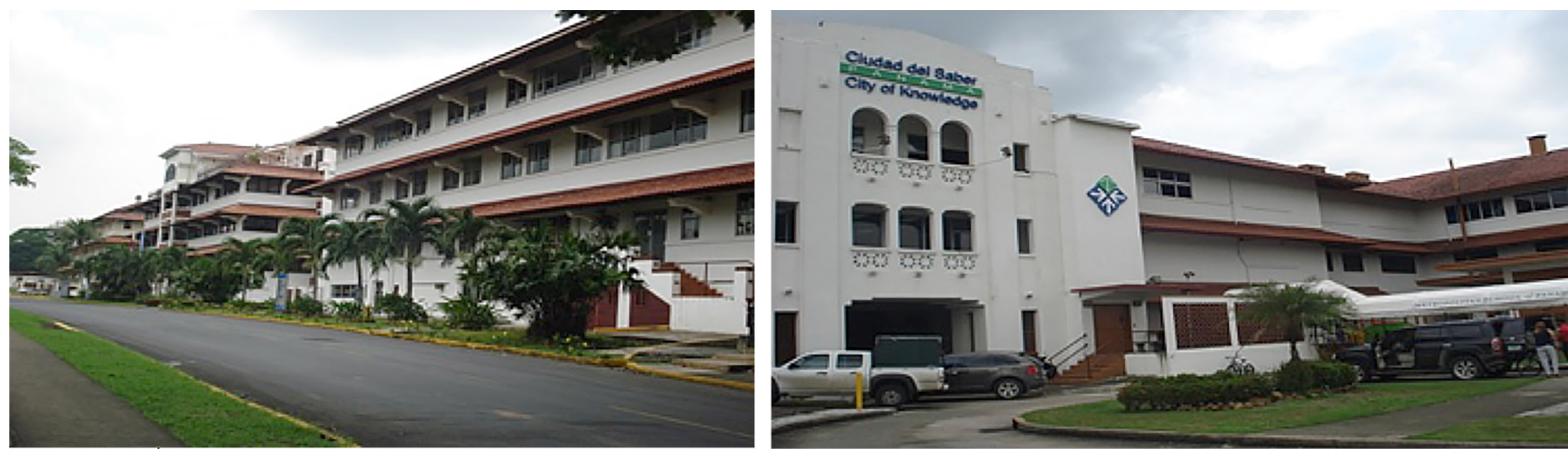

Figura 7. Ciudad del Saber. Fuente: Elaboración propia.
Como se puede apreciar, solo en este sector se recibió prácticamente una pequeña ciudad. Por lo tanto, asumir todos estos bienes, multiplicándolo por las otras áreas, era un gran reto de manejo por parte del gobierno panameño. Impulsados por el sentimiento nacionalista y sumado al resentimiento ante los estadounidenses después de tantos años de ocupación, se da la idea de crear un punto de encuentro y mediación (Arosemena, 2014). De este modo, se establece la Fundación Ciudad del Saber (FCDS), buscando dar uso a las instalaciones que se iban a recibir y transformar un centro de vocación militar en un área de construcción intelectual y artística. Sin embargo, según el actual presidente ejecutivo de la Fundación, se visualizó un proyecto de Panamá en el mundo, atrayendo inversión, aunque no dirigido directamente a la población panameña.

Después de tantos años de presencia extranjera, el proyecto se visualizó como "una salida hacia la libertad" (Arosemena, 2014). Así, un grupo constituido tanto por el sector privado como por académicos toman la decisión de crear una fundación sin fines de lucro privado y sin presiones políticas, concretándola en 1995. La junta directiva está constituida en primer lugar por el sector académico: los rectores de las tres universidades públicas, secretarios de las universidades y el grupo científico panameño. Además, se complementa por el sector privado: la familia Motta y Copa Airlines, escogiéndolos por "su éxito, tradición panameña, por ser respetados y libres de toda tendencia política" (Arosemena, 2014). Finalmente, aunque contradictorio al discurso de neutralidad política, se encuentran cuatro ministros del Estado y un representante de la Asamblea Nacional.

El establecimiento del proyecto y el nuevo uso de los bienes revertidos, fuera de las operaciones portuarias, posee un carácter simbólico muy importante. Lo anterior gracias a que Clayton sirvió como epicentro para las nuevas explotaciones de las antiguas instalaciones estadounidenses. Al comenzar desde cero, la fundación primero fue sufragada por la ARI. debido al estandarte de importancia que poseía el proyecto, no tanto para Ciudad de Panamá directamente, sino para ubicar la zona a nivel internacional y atraer inversión extranjera. 


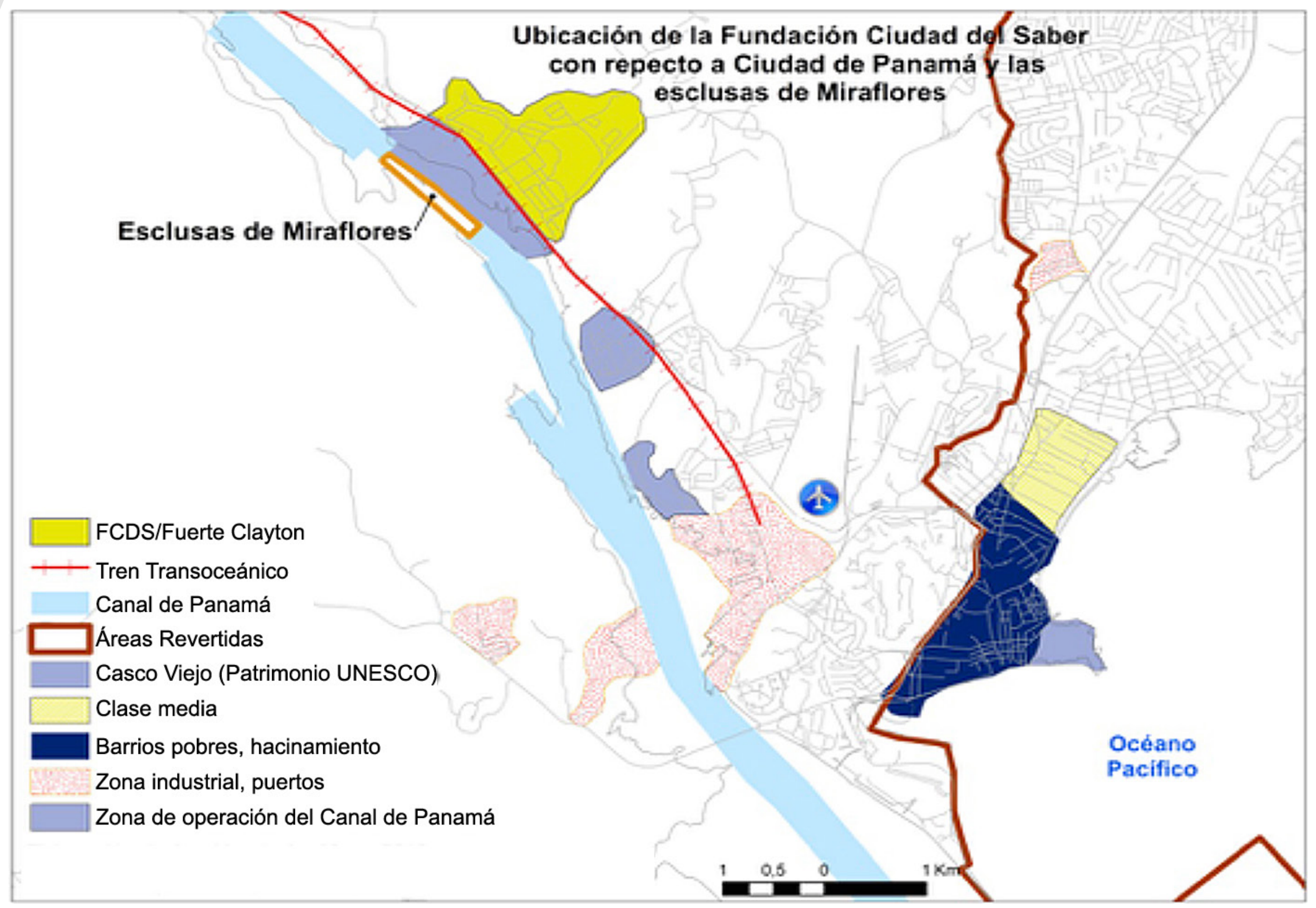

Figura 8. Ubicación de la Fundación Ciudad del Saber con respecto a Ciudad de Panamá y las esclusas de Miraflores.

Fuente: Elaboración propia.
Aprovechándose del momento histórico, se recibe el primer gran apoyo por parte de las entidades internacionales, siendo el Banco Interamericano de Desarrollo el que otorga el préstamo para la creación de un Tecnoparque. La idea original se basó en la creación de un centro de universidades con el fin de convertirlo en centro de intercambio de conocimiento académico entre laboratorios de investigación y empresas privadas (Arosemena, 2014), apostando por el conocimiento para atraer los primeros inversores a la zona. Además, se presenta la segunda parte del proyecto a la Unión Europea que plantea su visión futurista para cerrar la brecha entre el sector académico y el privado, siendo pionero en la región.

Los desarrolladores del proyecto FDCS, después de visitar el Centro Científico y Tecnológico de Montpellier en el 2002 y recibir misiones de expertos en la materia provenientes de la Unión Europea, se logra recibir el apoyo y se abre al mercado europeo. Estos dos puntos vienen a demostrar la idea de atraer intereses internacionales a Ciudad del Saber, pero si se observa, estos provienen del BID ubicado en Washington y de la UE, dejando de lado al sector latinoamericano.

De este modo, el proyecto se empieza a perfilar cada vez menos con la idea de entrar en una dinámica fluida metropolitana con el sector central de la capital. Por el contrario, aumenta la fragmentación, manteniéndose al margen de la vida diaria de la ciudad. Así, dentro del Tecnoparque se crea un ambiente de aceleración de las empresas de Panamá dirigido por Alberto Motta, uno de los miembros de la Junta Directiva. Además, con la colaboración del Banco Mundial, la Secretaría de Ciencia y Tecnología se abre a un espacio para nuevas ideas con el club de Inversionistas Privados. Por lo tanto, la FCDS llega a formarse como un facilitador de infraestructura, red, reuniones e intercambios con visión científica y de investigación, evidenciando la poca inclusión de la población en general

Como consecuencia de lo anterior, se ha creado una "Comunidad Internacional del Conocimiento" (Arosemena, 2014) y con la presencia del Instituto Smithsonian se crea el centro de estudios para la biodiversidad. Además, la UNICEF hizo la promoción del proyecto en el 2001, enfocándose también en el Hub de las Américas. Gracias a Copa Airlines, se atrajo el centro de operaciones de la ONU para América Latina (excepto la 
CEPAL), así como importantes ONGs y universidades internacionales. Por otro lado, la FCDS se ha vuelto un tipo de zona franca, donde se dan grandes ventajas para atraer inversión extranjera. Entre las principales ventajas se encuentran (FCDS, 2015):

a. Desgravación de impuestos a través de la afiliación a la Fundación Ciudad del Saber, en importación de maquinaria, exportación internacional, pagos locales, etc.

b. Infraestructura adaptable a las necesidades de la empresa.

c. Poseer beneficios para la inmigración de trabajadores, otorgando una visa especial de Ciudad del Saber, además de no poner un tope a la contratación de extranjeros.

Se encuentra a solo 15 minutos en vehículo del centro de Ciudad de Panamá, a cinco del centro turístico de Amador y a 45 de Colón: Ciudad del Saber es realmente una burbuja dentro de la dinámica metropolitana. Si bien existe un ambiente agradable con los servicios necesarios y la oportunidad de traer a sus propios empleados, las empresas no se relacionan con el resto de los panameños (Ericksen y Lopez, 2015). Esto debido a que los trabajadores de las entidades establecidas en el proyecto FCDS viven en los alrededores, en asentamientos que son también áreas revertidas. De estos, la mayoría son extranjeros, ya que no encuentran mano de obra local para sus operaciones. De este modo, se puede decir que si bien el proyecto ha atraído un tipo de inversión extrajera que antes no llegaba a Panamá, esta no se relaciona con el resto de la capital, ya que en este sitio se encuentra todo lo que se necesita sin tener que salir a buscar servicios o colaboradores, marcando aún más la fragmentación.

\section{Discusión:Lahuelladelainversiónextranjeraenel ÁreaMetropolitana Pacífica}

Desde su creación, Panamá se ha posicionado como un país especializado en el sector de servicios. Al haber siempre contado con una economía dolarizada, se facilitaron las transacciones internacionales. Además, la política pública promotora de negocios y atracción de inversión extranjera ha llevado a que el país tenga una de las economías que más rápido ha crecido en el mundo desde el 2001, a una tasa de 6.2\% en 2014 y un 5.8\% en 2015 (Banco Mundial, 2016). Estas cifras pueden representar una gran bonanza para el país, aunque se deben observar cuáles son las realidades de la población local, lo que viene a ser un reflejo de las ventajas o desventajas que posee Ciudad de Panamá.

Recordando que Panamá es un país con una fuerte política de competencia a nivel regional para atraer inversión extranjera liberalizando el mercado, esta dinámica crea desventajas que ponen freno al crecimiento económico. Ciudad de Panamá, con el gran cambio urbano que está viviendo, es ejemplo de nuevas centralidades que se desarrollan al exterior de la ciudad (Janoschka, 2002). Lo anterior puede fomentar no solo la fragmentación metropolitana, sino también una división social tanto económica como educativa que viene a impactar los intereses de inversiones en ciertos ámbitos.

Por lo tanto, una decisión política como factor desencadenante del gran auge de inversión extranjera en la capital, puede provocar resultados diferentes en ciertos sectores que generan deseconomías. Teniendo en cuenta que, desde el 2012 la estrategia más importante ha sido promocionar el país como espacio privilegiado para invertir, o, como dicen los políticos, "vender el país" (Brown y Luna, 2013). De este modo, la agresiva política de atracción de inversión en Panamá puede incentivar 0 desacelerar la inversión, pero más que todo golpear a la población que se encuentra a expensas de la globalización (Harvey, 2013).

Una de las principales ventajas que el país ha tenido es el crecimiento económico desde la caída del régimen de Manuel Noriega, gracias a la estabilidad política con la llegada de la democracia. Según el Î́ndice de Desarrollo Democrático de América Latina (IDDLAT), la democracia panameña era la cuarta más avanzada de toda la región, detrás de Costa Rica, Chile y Uruguay (Brown y Luna, 2013). Esto empieza a crear un ambiente adecuado para las políticas de apertura a las que se encuentra enfrentada la región. Se fomenta aún más la tradicional inversión en el sector de servicios, la cual ha sido el 
eje económico del país (Gordón, 2015). Aún más importante que una democracia firme (ya que durante varias décadas el país estuvo bajo dictadura militar), los empresarios y panameños dan como primera gran ventaja su posición geográfica. Panamá está en medio de las américas, sin embargo, éste no es un factor tan determinante, ya que otros países de la región tienen la misma posición. Lo es el haber explotado esta ventaja desde antes de la independencia (Mata y Rosas, 2014). No se debe obviar la importancia que tiene el Canal de Panamá, ya que fue esta obra la que hizo que el mundo volviera a su mirada al país por más que los dineros provenientes no se quedaran en el territorio, sino hasta después de la reversión total (Buendía, 2014).

Si bien el canal sigue siendo el principal punto geográfico de anclaje para sentirse en el Centro de las Américas, el concepto evolucionó gracias a la compañía Copa Airlines. Esta se ha encargado de poner a Ciudad de Panamá como Hub de la Américas, siendo un atractivo decisivo para que la inversión haya aumentado en los últimos años (Amaral, 2015; Ericksen y Lopez, 2015). La empresa ha desarrollado una conectividad hacia los principales destinos de América, logrando una dinámica entre el norte y el sur ideal para que las empresas se instalen al brindar vuelos a todos los países.

También el flujo financiero que pasa por el Centro Bancario vio un aumento gracias a las acciones del estado para sacar al país de las Listas Negras, evitando la doble tributación (Buendía, 2014). Sin embargo, todavía se sigue protegiendo cierta información bancaria confidencial y a las empresas offshore, como se puede constatar en los casos recientes de los Panama Papers.

Para las empresas son importantes la estabilidad jurídica y las facilidades que da el país para empezar a operar (Martinez, 2014). Esta es otra de las grandes ventajas que se encuentran en el país, ya que posee el segundo lugar en Latinoamérica y el Caribe a la hora de abrir un negocio, por lo mismo, la Ciudad de Panamá es considerada la mejor ciudad de Centroamérica para hacer negocios (Banco Mundial, 2014). Sumado a la estabilidad jurídica, Panamá puso en práctica el "Crisol de Razas", acción por la cual se agilizaban los procesos migratorios a los extranjeros para poder obtener a corto plazo el permiso de trabajo. Esta política tuvo que ser modificada desde junio del 2016, lo que vino a regular la importante migración que se estaba llevando a cabo en el país desde el gobierno del expresidente Ricardo Martinelli (López, 2016).

También se debe resaltar la importancia de la inversión en la obra pública realizada por el gobierno de Panamá. Mejorar la infraestructura llevó a la ciudad a dejar de ser "un pueblo" (Amaral, 2015), aspecto importante para traer más servicios complementarios como restaurantes, teatros, museos, etc., y así, mejorar el nivel de vida. A los anteriores se le suman las grandes obras de infraestructura pública como la Línea de Metro, la Cinta Costera, la nueva terminal del Aeropuerto Internacional Tocumen y el Corredor Sur, entre otras, sin dejar de lado la gran ampliación que se hizo del Canal de Panamá.

Finalmente, con las Áreas Revertidas es cuando Panamá empieza a dinamizar la economía metropolitana. Si bien las operaciones de la vía marítima han dejado grandes ganancias al país, son las zonas aledañas al canal las que vienen a dinamizar realmente y abrir oportunidades a la inversión extranjera. El país decide darles uso comercial a miles de hectáreas de las mejores tierras del país sin uso anterior con apertura a todo tipo de negocios y los inversionistas aprovechan las licitaciones sabiendo que Panamá no puede mantenerlas (Gordón, 2015).

Dentro de la antigua zona norteamericana se han desarrollado todo tipo de negocios, desde los tradicionales servicios portuarios hasta, como se ha visto, proyectos innovadores en la región centroamericana, además de centros turísticos. Aprovechando la riqueza paisajística, se han desarrollado también nuevos puertos y marinas para yates y veleros, sin obviar la construcción del costoso Museo de la Biodiversidad, diseñado por Frank Gehry. Se observa, por tanto, una importante migración de inversión a esta zona desde el 2000, alterando la lógica metropolitana tradicional de Ciudad de Panamá como único polo de atracción de la inversión extranjera. 


\section{Referencias bibliográficas}

ACOBIR. (1998). Región Interoceánica: el reto inmediato (Memoria ACOBIR). Ciudad de Panamá: Unidad Administrativa de Bienes Revertidos.

Amaral, R. (2015). Western Union, General Manager \& Country Director.

ARI. (1994). La Reversión: el gran reto Nacional. Ciudad de Panamá: Unidad Administrativa de Bienes Revertidos.

Arosemena, J. (2014, mayo). Presidente Ejecutivo, Ciudad del Saber.

Banco Mundial. (2016). Panoráma Económico de Panamá. Banco Internacional para la Reconstrucción y el Desarrollo.

Banco Mundial. (2014). Doing Business en Centroamérica y la República Dominicana 2015. Banco Internacional para la Reconstrucción y el Desarrollo.

Barrera, B. (2015). Areas Revertidas, Ejecutiva de Promoción.

Brown, H., Luna, I. (2013). Panamá: el crecimiento económico a expensas de la política. Revista de ciencia política (Santiago), 33(1), 287-301. Recuperado de: https:// doi.org/10.4067/S0718-090X2013000100014"

Buendía, G. (2014, mayo). Especialista en economía regional, editora de la revista de negocios y mercado Pauta.

CAPAC. (2015). Edificaciones comerciales y recidenciales. Construcción, la industria del bienestar humano, (55).

Cárdenas, C., Isabel, M., Cabrera Marrero, F., y Pittí de Rivera, A. (2015).

Poblaciones urbana y rural de Panamá. Un análisis a partir de microdatos censales. Revista Novedades en Población, 11(22).

Castro Gómez, C. D. (2012). Mega crecimiento urbano de la ciudad de Panamá y su impacto sobre el hábitat y la vivienda popular. Dimensiones del Habitat popular latinoamericano (Consejo Latinoamericano de Ciencias Sociales, pp. 75-99). Quito, Ecuador: FLACSO Ecuador Instituto de la Ciudad CLACSO.

CIA. (2017). The World FactBook, Hong Kong. [Gobierno].

Collin-Delavaud, A. (2006). L'insertion du centre historique et de la zone urbaine du canal dans l'aire métropolitaine de Panamá. L'Information géographique, 70(2), 21-34.

Collin-Delavaud, A. (2011). La région centrale du Panama, un nouvel espace mondial? L'Information géographique, 75(2), 25-48.

de Brown, L. V. (2014, abril). Municipalidad de Panamá.

Ericksen, L., y Lopez, C. (2015). TV5 Monde, France. Responsables de marketing et Solutions.

FCDS. (2015). Fundación Ciudad del Saber, City of Knowledge. Recuperado de http:// ciudaddelsaber.org/es"

Ghorra-Gobin, C. (2015). La metropolisation en question. La ville en debat (1a ed.). Paris, Francia: Presse Universitaires de France.

Gordón Canto, R. (2015, mayo). Decano facultad de Economía, Universidad de Panamá. Harvey, D. (2013). The Politics of Public Space. Routledge.

Heritage Foundation. (2016). Hong Kong Economy: Population, Facts, GDP,

Business, Trade, Inflation. Recuperado el 25 de enero de 2017, de http://www.heritage. org/index/country/hongkong"

Herrera, L., y Castro, G. (1986). La distribución espacial y las migraciones de la población de Panamá. 1903-2003, cien años de la independencia de Panamá (pp. 133-143). Universidad de Panamá.

INEC. (2015). Panamá en Cifras, Instituto Nacional de Estadística y censos. 20102014. Ciudad de Panamá: Contraloría General de la República de Panamá. 
Janoschka, M. (2002). El nuevo modelo de la ciudad latinoamericana: fragmentación y privatización. EURE (Santiago), 28(85), 11-20. https://doi.org/10.4067/S025071612002008500002" https://doi.org/10.4067/S0250-71612002008500002

López Guía, A. (2016, junio). Gobierno de Panamá comienza a dar citas para nuevo decreto de regularización migratoria. La Prensa. Recuperado de: https:// www.prensa.com/sociedad/Gobierno-Panama-comienza-regularizacionmigratoria_0_4513798727.html

Luna, C. I., y Sánchez, S. (2009). Panamá: paraíso imperfecto. Revista de ciencia política (Santiago), 29(2), 533-564. https://doi.org/10.4067/S0718-090X2009000200014"

Martinez, E. (2014, abril). Gerente General del PH Ocean Plaza.

Mata, A., y Rosas, I. (2014, abril). Ministerio de Vivienda y Ordenamiento Territorial.

Rivera Evans (junio 2011) Panamá: Centro Bancario Internacional de Latinoamérica. http://www.superbancos.gob.pa/documentos/temasfreq/Hub_Financiero_para_ las_Americas.pdf"

Soto, G. (2014, abril 10). La tercera fase de la Cinta Costera empieza a funcionar. Panamá América. Recuperado de http://www.panamaamerica.com.pa/content/latercera-fase-de-la-cinta-costera-empieza-funcionar"

Tejeira Davis, E. (2008). El Casco Antiguo de Panamá. Biblioteca Nacional de Panamá.

UABR. (1998a). Caracterización Socioeconómica de la Región Interoceánica. Departamento de Gestión Ambiental. (Dirección de administración de los Bienes Revertidos). Ciudad de Panamá: Unidad Administrativa de Bienes Revertidos.

UABR. (1998b). Memoria de las Areas Revertidas 1996-1997. Ciudad de Panamá: Unidad Administrativa de Bienes Revertidos.

UABR. (1999a). Inventario de Bienes Revertidos 1979-1999 (p. 70). Ciudad de Panamá: Unidad Administrativa de Bienes Revertidos.

UABR. (1999b). Memoria de las Areas Revertidas 1997-1998. Ciudad de Panamá: Unidad Administrativa de Bienes Revertidos.

Young A, R. (2013). Rascacielos de la Ciudad de Panamá. Construcción, la industria del bienestar humano, 4-11. 